\title{
Adamantane resistance in seasonal human influenza A viruses from Calgary, Alberta (January 2007 to August 2008)
}

\author{
Kanti Pabbaraju MSc ${ }^{1}$, Sallene Wong BSc ${ }^{1}$, Dmitri K Kits ${ }^{2}$, Julie D Fox PhD ${ }^{1,3}$
}

\author{
K Pabbaraju, S Wong, DK Kits, JD Fox. Adamantane resistance \\ in seasonal human influenza A viruses from Calgary, Alberta \\ (January 2007 to August 2008). Can J Infect Dis Med Microbiol \\ 2010;21(2):e87-e91.
}

The available antivirals for the treatment and prophylaxis of influenza A infections include the adamantanes (amantadine and rimantadine), which are matrix (M2) protein inhibitors, and the neuraminidase inhibitors (oseltamivir and zanamivir). Resistance to the adamantanes is conferred by mutations at amino acid positions $26,27,30,31$ or 34 within the M2 protein of influenza A viruses. A significant increase in adamantane resistance has been reported worldwide since 2003, reflected by a similar increase in Canada. The present study reports on the frequency of adamantane resistance in seasonal influenza A viruses in Calgary, Alberta, for the period between January 2007 and August 2008, as an update to the previous report. Positive influenza A samples (221 original patient specimens and 34 isolates obtained by viral culture) were analyzed for changes in the critical amino acid residues of the $\mathrm{M} 2$ gene. The amplification and sequencing of regions that confer adamantane resistance directly from RNA extracts of clinical samples (without previous culture) makes this approach a fast and efficient process for monitoring resistance. The results showed that the frequency of resistance varied from $37.5 \%$ to $49.2 \%$ in circulating influenza A H3N2 virus strains $(n=213)$ between January 2007 and April 2007. The frequency of resistance increased to $100 \%$ in May 2007, after which all H3N2 viruses were resistant until the end of the monitoring period. All resistant $\mathrm{H} 3 \mathrm{~N} 2$ viruses contained the serine to asparagine substitution at amino acid position 31. Resistance was not observed in the H1N1 viruses tested $(n=39)$ within this monitoring period. The level of adamantane resistance in $\mathrm{H} 3 \mathrm{~N} 2$ viruses continues to remain high since resistant viruses became the prevalent circulating strains in 2005. Recent reports have indicated that the currently circulating swine-origin influenza A H1N1 subtype viruses are adamantane resistant. It is, thus, important to continue to monitor seasonal influenza A viruses for antiviral resistance markers to ensure optimal prophylaxis and treatment.

\author{
La résistance à l'adamantane des virus humains \\ et saisonniers de la grippe $\mathrm{A}$ à Calgary, en \\ Alberta (janvier 2007 à août 2008)
}

Les antiviraux offerts pour le traitement et la prophylaxie des infections par la grippe A sont les adamantanes (amantadine et rimantadine), des inhibiteurs de la protéine matricielle (M2), et les inhibiteurs de la neuraminidase (oseltamivir et zanamivir). La résistance aux adamantanes est conférée par des mutations aux positions 26, 27, 30, 31 ou 34 des acides aminés de la protéine M2 des virus de la grippe A. Depuis 2003, on rend compte d'une augmentation marquée de la résistance à l'adamantane dans le monde, observée également au Canada. Le présent article décrit la fréquence de la résistance à l'adamantane des virus humains et saisonniers de la grippe A à Calgary, en Alberta, entre janvier 2007 et août 2008, afin de mettre à jour le rapport précédent. Les auteurs ont analysé des échantillons de grippe A positifs (221 échantillons originaux de patients et 34 isolats obtenus par culture virale) pour déceler des changements dans les résidus critiques d'acides aminés du gène M2. L'amplification et le séquençage des régions qui confèrent la résistance à l'adamantane directement des extraits d'ARN prélevés sur des échantillons cliniques (sans culture antérieure) font de cette démarche un processus rapide et efficace pour surveiller la résistance. Les résultats ont révélé que la fréquence de résistance variait de 37,5\% à 49,2\% dans les souches du virus de la grippe A H3N2 en circulation $(n=213)$ entre janvier et avril 2007. La fréquence de la résistance est passée à $100 \%$ en mai 2007, puis tous les virus $\mathrm{H} 3 \mathrm{~N} 2$ sont demeurés résistants jusqu'à la fin de la période de surveillance. Tous les virus H3N2 résistants contenaient la substitution sérine à asparagine à la position 31 de l'acide aminé. On n'a pas observé de résistance dans les virus H1N1 $(\mathrm{n}=39)$ étudiés au cours de cette période de surveillance. Le taux de résistance à l'adamantane dans les virus H3N2 continue de demeurer élevé, car les virus résistants sont devenus les souches en circulation les plus prévalentes en 2005. Selon de récents rapports, les virus de sous-type A H1N1 d'origine porcine sont résistants à l'adamantane. Il est donc important de poursuivre la surveillance des virus saisonniers de la grippe A afin de connaître les marqueurs de résistance antivirale et d'ainsi assurer une prophylaxie et un traitement optimaux.

Key Words: Adamantane; Amantadine; Antiviral; Influenza; M2 protein; Resistance

Curveillance of seasonal influenza A (IFVA) isolates for resistSance to antivirals, such as the adamantanes (amantadine and rimantadine), is valuable to ensure appropriate patient and outbreak management. The adamantane class of antivirals can be used for prophylaxis and, in some circumstances, treatment of influenza infections in an outbreak setting, and also in cases for which vaccination is not an option. Monitoring for adamantane resistance is particularly important given the recent reports (1) of the increasing frequency of resistance to the neuraminidase class of inhibitors (eg, oseltamivir and zanamivir), especially in the IFVA H1N1 subtype viruses. Sequence information on the currently circulating novel swine-origin influenza virus that was reported to have sustained human-to-human transmission showed that these strains are resistant to the adamantane class of antivirals (2).

The adamantane class of antivirals inhibit viral replication by blocking the ion-channel activity of the IFVA matrix (M2) protein, thus preventing viral replication $(3,4)$. The markers for adamantane resistance have been characterized and are associated with changes at amino acid positions 26, 27, 30, 31 and 34 in the M2 protein (5,6). A sharp increase in the levels of adamantane resistance has been noted worldwide in IFVA

\footnotetext{
${ }^{1}$ Provincial Laboratory for Public Health (Microbiology), Calgary; ${ }^{2}$ Department of Biological Sciences, University of Alberta, Edmonton;

${ }^{3}$ Department of Microbiology and Infectious Diseases, University of Calgary, Calgary, Alberta

Correspondence: Kanti Pabbaraju, Provincial Laboratory for Public Health (Microbiology), 3030 Hospital Drive, Calgary, Alberta T2N 4 W4.

Telephone 403-944-8621, fax 403-283-0142, e-mail K.Pabbaraju@provlab.ab.ca
} 
subtype H3 viruses since 2003 (7-9). Elevated resistance levels were also reported in Canada by the National Microbiology Laboratory (NML, Public Health Agency of Canada, Winnipeg, Manitoba [www.phac-aspc.gc.ca/fluwatch/]). The Provincial Laboratory for Public Health in Calgary, Alberta, published a comprehensive study (10) on the levels of adamantane resistance in Alberta from 1970 to January 2007. The study adds to previous reports by determining the frequency of adamantaneresistant strains in circulating $\mathrm{H} 3 \mathrm{~N} 2$ and $\mathrm{H} 1 \mathrm{~N} 1$ subtype viruses from January 2007 to August 2008 in Alberta. The data presented also enhances the available global information on the distribution of adamantane-resistant IFVA. We will continue to monitor the level of adamantane resistance in circulating IFVA $\mathrm{H} 3$ and $\mathrm{H} 1$ subtypes in Alberta, prospectively, which will provide information relevant to the management of severe infections and outbreaks.

\section{METHODS}

\section{Study samples}

A total of 255 IFVA-positive samples (original specimens) or virus isolates (obtained from respiratory samples after culture), identified at the Provincial Laboratory for Public Health from January 2007 to August 2008, were used for the study. All samples/isolates were screened for genetic markers of adamantane resistance. Of these, 136 samples/isolates from 2007 were tested (including 126 of the $\mathrm{H} 3$ subtype and nine of the $\mathrm{H} 1$ subtype; one specimen could not be subtyped, possibly due to low viral load) and 119 from 2008 (including 87 of the H3 subtype and 30 of the $\mathrm{H} 1$ subtype; two specimens could not be subtyped). IFVA isolates were cultured from 34 respiratory samples by inoculating Rhesus monkey kidney cells (Diagnostic Hybrids, USA). Total nucleic acid was extracted directly from 221 samples. A total of $213 \mathrm{H} 3$ subtype and $39 \mathrm{H} 1$ subtype influenza A viruses were included in the study.

Two hundred thirty-four respiratory samples included in the present study were collected from the upper respiratory tract $(91.76 \%)$ and comprised of nasopharyngeal, nasal, throat, saliva, auger suctions and buccal samples; 19 were collected from the lower respiratory tract $(7.45 \%)$ including bronchoalveolar lavage and sputum; and two specimens $(0.78 \%)$ were fluid/ swabs from an unrecorded source.

Patients' ages ranged from 12 days to 98 years, with a mean of 36 years; $58.3 \%$ of samples were from males and $41.7 \%$ were from females.

\section{Nucleic acid extraction}

Nucleic acid extraction from IFVA isolates grown in Rhesus monkey kidney cells or from respiratory samples was performed using the easyMAG extractor (bioMérieux Inc, USA). Extraction from $200 \mu \mathrm{L}$ of culture material/original sample was performed according to the manufacturer's instructions using an elution volume of $110 \mu \mathrm{L}$, yielding total nucleic acid.

\section{Nucleic acid tests for detection and subtyping of IFVA}

The nucleic acid tests used for IFVA screening were performed by nucleic acid sequence-based amplification on the easyQ (bioMérieux Inc) (10) and the xTag Respiratory Viral Panel on the Luminex platform (Luminex Molecular Diagnostics Inc, Canada). The results obtained on the nucleic acid sequencebased amplification platform were qualitative and did not provide an estimate of the viral load or subtype. The Respiratory Viral Panel assay provided the subtype of the virus, but the median fluorescence intensity did not provide an indication of the viral load in the sample. To subtype the IFVA isolate and estimate the viral load, all screen-positive extracts were subjected to a real-time reverse transcriptase polymerase chain reaction (RT-PCR) assay using hydrolysis probes targeting the hemagglutinin genes of $\mathrm{H} 1$ and $\mathrm{H} 3$ subtype viruses (2). The RT-PCR was performed on the SDS 7500 from Applied Biosystems (ABI, USA), with the cycle threshold (Ct) allowing estimation of the viral load to differentiate between weak and strong samples. The authors attempted to establish a cut-off $\mathrm{Ct}$ value to determine which samples would need to be cultured to provide enough target transcript to determine adamantane resistance. The sequence obtained directly from the specimen was compared with that from the cultured virus to determine whether there were sequence changes as a result of virus propagation.

\section{One-step RT-PCR for amplification of the M2 gene}

One-step RT-PCR reactions were performed for amplification of part of the M2 gene as reported previously (11). The One-Step RT-PCR Kit (Qiagen, Canada) with RNaseOUT (Invitrogen, USA) was used for amplification. Primers FluA-AmanRes-For (5'-CAAATGGCTGGATCGAGTGAG-3') and FluAAmanRes-Rev (5'-GTTCCTTTCGATATTCTTCCCTC-3') were designed to amplify and sequence a 355 base pair fragment of the M2 protein, including the region of interest determining adamantane resistance. All thermal cycling was performed using a 2720 Thermal Cycler (ABI). The PCR products were purified using QIAquick columns (Qiagen) and eluted in $50 \mu \mathrm{L}$ of molecular grade water.

\section{Cycle sequencing and analysis}

Amplified products were sequenced in both directions using the ABI Prism Big Dye Terminator v3.1 Cycle Sequencing kit in the ABI Prism 3130-Avant Genetic Analyzer (Applied Biosystems) on a $50 \mathrm{~cm}$ array. Data collection was undertaken using the Applied Biosystems Software v3.0. The sequencing reaction was performed according to the manufacturer's protocol as described previously (11). The sequences were analyzed by the Sequencing Analysis Software v5.3 (Applied Biosystems) and alignments were performed using ClustalW v1.4 included in BioEdit v7.0.0 (www.mbio.ncsu.edu/BioEdit/bioedit.html).

\section{RESULTS}

\section{Assessment of RT-PCR and sequencing sensitivity for} IFVA screen-positive samples and culture harvests

A total of 255 IFVA screen-positive nucleic acid extracts were assessed for adamantane resistance by sequencing the M2 region coding for adamantane resistance. These included extracts from 221 specimens, 24 isolates and 10 cases, in which both original specimens and isolates were analyzed. The $\mathrm{Ct}$ values were used as an indicator of viral load and the $\mathrm{Ct}$ for specimens/isolates obtained by the subtyping assay ranged from 17.01 to 43.04 , with a mean of 29.60. Sequencing results were obtained from 232 extracts of specimens/isolates (90.98\%); the $\mathrm{Ct}$ value for these ranged from 17.01 to 41.7 , with a mean \pm SD of $28.91 \pm 5.72$, respectively. Sequencing results could not be obtained from 18 specimens and five isolates. Of the 
TABLE 1

Monthly distribution of $\mathrm{H} 1$ and $\mathrm{H} 3$ samples tested

\begin{tabular}{lcc}
\hline Month, year & H1 tested, $\mathbf{n}$ & H3 tested, $\mathbf{~}$ \\
\hline January, 2007 & 3 & 24 \\
February, 2007 & 1 & 13 \\
March, 2007 & 1 & 54 \\
April, 2007 & 0 & 11 \\
June, 2007 & 1 & 1 \\
July, 2007 & 1 & 1 \\
October, 2007 & 0 & 1 \\
November, 2007 & 0 & 4 \\
December, 2007 & 2 & 7 \\
January, 2008 & 15 & 13 \\
February, 2008 & 5 & 13 \\
March, 2008 & 2 & 24 \\
April, 2008 & 2 & 16 \\
May, 2008 & 1 & 10 \\
August, 2008 & 0 & 1 \\
\hline
\end{tabular}

18 specimens, subtyping result was not available for two specimens, and the Ct values for the remaining samples ranged from 33.25 to 40.59 (mean \pm SD $37.10 \pm 2.24$ ) indicating that these samples had a lower viral load than those for which sequencing was successful. Of the five isolates that could not be sequenced, there was no $\mathrm{Ct}$ for one isolate using the IFVA subtyping assay and the $\mathrm{Ct}$ range for the remaining isolates ranged from 40.14 to 43.04 , suggesting that inefficient propagation of the virus in culture and subsequent low viral load was the likely explanation for the failure.

Good-quality sequence data were obtained from 203 of 221 original samples $(91.85 \%), 19$ of 24 cell culture harvests $(79.16 \%)$ and 10 of 10 cases (100\%), in which original sample and culture harvest were analyzed across the region of interest. No sequence variation was observed across the amplified region when results for culture harvest and original sample $(n=10)$ were compared.

\section{Subtype distribution and prevalence of adamantane} resistance in IFVA-positive samples

All specimens and culture harvests were subtyped as described above. There were $39 \mathrm{H} 1$ and $213 \mathrm{H} 3$ subtypes with three samples that could not be subtyped, likely due to a low IFVA load. The number of positive specimens detected and typed varied through the year (Table 1 ).

Of the $\mathrm{H} 3$ samples for which good sequence data were obtained, 144 were resistant and 52 were sensitive to adamantanes ( $73.47 \%$ resistant [144 of 196 sequence results]). Of the 144 resistant samples, 136 sequences were obtained directly from the specimen extract, four from the harvest and four from both specimen and harvest. Of the 52 sensitive samples, 50 sequences were obtained from specimen extract and two from harvest. No mutations conferring resistance to adamantanes were found in $36 \mathrm{H} 1$ subtype viruses that were successfully sequenced. Of the $36 \mathrm{H} 1$ subtype viruses, 17 were sequenced directly from specimen, 13 from harvest and six from both specimen and harvest. Figure 1 shows the monthly distribution of adamantane resistance from January 2007 to August 2008 for $\mathrm{H} 3$ viruses. The level of resistance in the IFVA subtype $\mathrm{H} 3$ viruses ranged from $37.5 \%$ to $49.2 \%$ from

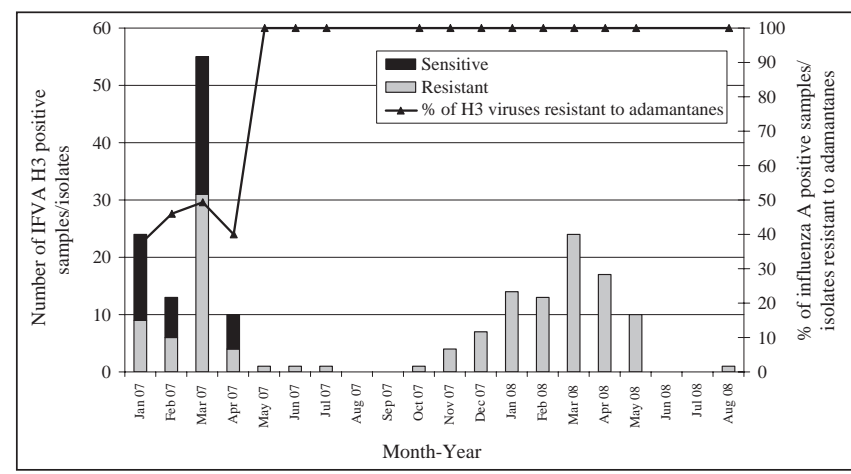

Figure 1) Monthly distribution of adamantane resistance in influenza A (IFVA) H3-positive samples/isolates tested from January 2007 to August 2008. The total number of sensitive and resistant samples detected during the different months and the percentage of viruses showing markers of resistance are shown

January 2007 to April 2007 ( $n=110)$. All the IFVA subtype H3 viruses tested from May 2007 up to August 2008 were resistant to adamantanes $(\mathrm{n}=103)$.

Fifteen of the specimens/isolates included in the study were from respiratory outbreaks at long-term and assisted care centres, four from schools, and 236 were individual cases unrelated to outbreaks. Among the specimens collected from outbreaks, one sample gave a positive result for IFVA subtype H1, and 18 samples gave a positive result for IFVA subtype $\mathrm{H} 3$ viruses. Of the IFVA $\mathrm{H} 3$ viruses from outbreaks for which sequencing was successful, six were sensitive and nine were resistant to adamantanes. All six sensitive $\mathrm{H} 3$ samples were obtained from January to March 2007; IFVA H3 viruses tested after March 2007 all contained mutations that conferred resistance to adamantanes.

Amino acid changes observed leading to resistance

All 144 resistant virus strains identified in the present study (144 resistant of 255 tested) contained the serine to asparagine substitution at amino acid positon 31 (S31N). No changes from the sensitive (wild type) sequence were detected for amino acid positions $26,27,30$ and 34 .

\section{DISCUSSION}

The adamantane class of antivirals can be used in restricted circumstances for the prophylaxis and treatment of IFVA infections, especially in institutional settings and in patients who cannot be vaccinated. However, the utility of this antiviral has diminished with the increased frequency of resistance in the circulating IFVA subtype H3N2 viruses worldwide. The global frequency of adamantane resistance was low before $2003(7,12)$. An increase in adamantane resistance was first detected in Asia starting in 2003 (7) and the resistant strains subsequently spread worldwide (7-9,13). A similar pattern of high-level resistance has been observed in Canada $(11,14)$; adamantane resistance continues to remain high in North America (15) (www.cdc. gov/mmwr/mmwrpvol.html). As presented in the current report, the level of resistance from January 2007 to August 2008 was $73.47 \%$ in the IFVA subtype $\mathrm{H} 3$ viruses, resulting from changes at amino acid position 31 of the M2 protein. Resistance levels were low at the beginning of 2007, but spiked in the latter half of the year and have remained high. According to the Public 
Health Agency of Canada, the level of adamantane resistance was $37 \%$ in the 2006/2007 influenza season (Flu Watch: August 12, 2007 to August 25, 2007 [week 33 to 34]) and 99.6\% in the 2007/2008 influenza season (Flu Watch: July 13, 2008 to July 26, 2008 [week 29 to 30]). Strain characterization was performed at the NML showing that the predominant circulating subtype in the 2006/2007 season was similar to A/ Wisconsin/67/2005 (H3N2), and the major strain circulating in 2007/2008 was similar to A/Brisbane/10/2007 (H3N2). The IFVA strains circulating in Alberta were similar to those reported by the NML based on hemagglutination inhibition performed on representative positive samples (data not shown). Other studies have shown the circulation of resistant and sensitive strains during this time period (16).

Adamantane resistance in the IFVA subtype $\mathrm{H} 1$ viruses continues to remain low in Canada. Two recently published studies $(11,14)$ reporting the rates for adamantane resistance in Canada did not detect any resistant viruses of the H1N1 subtype. A low frequency of adamantane resistance had been reported by the NML ( $1 \%$ in both the 2006/2007 and the 2007/2008 influenza seasons for H1 viruses. Flu Watch: July 13, 2008 to July 26, 2008 [week 29 to 30]; Flu Watch: August 12, 2007 to August 25, 2007 [week 33 to 34]). The circulation of sensitive and resistant IFVA H1 subtype viruses has been reported in other countries $(8,9,17)$, with resistance reaching $15.5 \%$ worldwide and 4\% in the United States in 2005/2006.

Previous reports have speculated that the origin of the S31N amino acid change could be a random mutation or could be drug induced as a result of the overuse of adamantanes in Southeast Asia. The rampant, worldwide spread of the strain with this mutation could be the result of a selective advantage of the S31N mutants for growth and proliferation. Alternatively, the selective advantage may be conferred by a mutation located elsewhere in the viral genome and the resistant M2 gene may have recombined with this strain. Complete genome and phylogenetic studies have shown that the adamantane-resistant viruses belong to a distinct lineage (the $\mathrm{N}$ lineage) characterized by 17 amino acid replacements across the genome $(16,18)$. It has also been shown that IFVA viruses with the resistant mutation have similar fitness compared with the sensitive viruses and, thus, may not be selected for reversion (19). Nelson et al (20) have recently reported that strains with the S31N mutation were independently

\section{REFERENCES}

1. Sheu TG, Deyde VM, Okomo-Adhiambo M, et al. Surveillance for neuraminidase inhibitor resistance among human influenza $A$ and $B$ viruses circulating worldwide from 2004 to 2008. Antimicrob Agents Chemother 2008;52:3284-92.

2. Dawood S, Jain S, Finelli L, et al. Emergence of a novel swineorigin influenza $A(H 1 N 1)$ virus in humans. N Engl J Med 2009;360:2605-15.

3. Wang C, Takeuchi K, Pinto LH, Lamb RA. Ion channel activity of influenza A virus M2 protein: Characterization of the amantadine block. J Virol 1993;67:5585-94.

4. Pielak RM, Schnell JR, Chou JJ. Mechanism of drug inhibition and drug resistance of influenza A M2 channel. Proc Natl Acad Sci 2009; 106:7379-84.

5. Belshe RB, Smith MH, Hall CB, Betts R, Hay AJ. Genetic basis of resistance to rimantadine emerging during treatment of influenza virus infection. J Virol 1988;62:1508-12.

6. Hay AJ, Zambon MC, Wolstenholme AJ, Skehel JJ, Smith MH. Molecular basis of resistance of influenza A viruses to amantadine. J Antimicrob Chemother 1986;18(Suppl B):19-29. introduced in different geographical locations; however, the majority of resistant viruses circulating globally originated from Hong Kong in 2003. Continued antiviral use is not required to maintain the resistant strain in a population, suggesting that selective pressure is not exerted by the use of adamantanes. Prophylaxis using adamantanes was halted in January 2006, based on an advisory issued by the Centers for Disease Control and Prevention (USA); however, the frequency of resistant strains continues to remain high (15).

The other major class of anti-influenza drugs include the neuraminidase inhibitors. A recent study has shown that the level of resistance to the neuraminidase inhibitors increased sharply in the United States starting in October 2007, especially in $\mathrm{H} 1$ subtype viruses, and continues to remain high; although, to date, $\mathrm{H} 3$ viruses resistant to neuraminidase inhibitors seem to be rare $(1,15)$. Emerging resistance to oseltamivir, a neuraminidase inhibitor used most frequently for IFVA prophylaxis and treatment, complicates the management of infected patients and makes subtyping and resistance determination for circulating strains very important. Guidelines for treatment and prophylaxis, provided by the Centers for Disease Control and Prevention, are now based on the subtype of the circulating IFVA (www.ncbop.org/PDF/CDCAdvisoryDec2008Influenza.pdf).

With high levels of adamantane resistance in the circulating seasonal IFVA subtype $\mathrm{H} 3$ and the novel H1N1 swine-origin influenza viruses, as well as high levels of oseltamivir resistance in the seasonal IFVA H1 viruses, testing all IFVA-positive samples to determine the subtype and antiviral resistance pattern is a requirement. The ability to perform this type of testing directly on nucleic acids extracted from the specimen without need for previous culture can provide rapid and timely results. Allen et al (21) have highlighted the need for monitoring genetic variation to predict events that lead to new circulating influenza strains. Prevention and treatment strategies will have to vary based on these results. It is also vitally important to have these testing protocols in place for pandemic preparedness, so that emerging and novel influenza viruses can be analyzed and appropriate management can be instigated.

ACKNOWLEDGEMENTS: Funding for the study was provided by Alberta Health \& Wellness. DKK was supported by the Summer Temporary Employment Program (STEP, Alberta Health Services).

7. Bright RA, Medina MJ, Xu X, et al. Incidence of adamantane resistance among influenza A (H3N2) viruses isolated worldwide from 1994 to 2005: A cause for concern. Lancet 2005;366:1175-81.

8. Bright RA, Shay DK, Shu B, Cox NJ, Klimov AI. Adamantane resistance among influenza $\mathrm{A}$ viruses isolated early during the 2005-2006 influenza season in the United States. JAMA 2006;295:891-4.

9. Deyde VM, Xu X, Bright RA, et al. Surveillance of resistance to adamantanes among influenza $\mathrm{A}(\mathrm{H} 3 \mathrm{~N} 2)$ and $\mathrm{A}(\mathrm{H} 1 \mathrm{~N} 1)$ viruses isolated worldwide. J Infect Dis 2007;196:249-57.

10. Moore C, Hibbitts S, Owen N, et al. Development and evaluation of a realtime nucleic acid sequence based amplification assay for rapid detection of influenza A J Med Virol 2004;74:619-28.

11. Pabbaraju K, Ho KC, Wong S, et al. Adamantane resistance in circulating human influenza A viruses from Alberta, Canada (1970-2007). Antiviral Res 2008;79:81-6.

12. Ziegler T, Hemphill ML, Ziegler ML, et al. Low incidence of rimantadine resistance in field isolates of influenza A viruses. J Infect Dis 1999;180:935-9. 
13. Saito R, Li D, Suzuki H. Amantadine-resistant influenza A (H3N2) virus in Japan, 2005-2006. N Engl J Med 2007;356:312-3.

14. Higgins RR, Eshaghi A, Burton L, Mazzulli T, Drews SJ. Differential patterns of amantadine-resistance in influenza A (H3N2) and (H1N1) isolates in Toronto, Canada. J Clin Virol 2009;44:91-3.

15. Update: Influenza activity - United States, September 28, 2008-April 4, 2009, and composition of the 2009-10 influenza vaccine. MMWR Morb Mortal Wkly Rep 2009;58:369-74.

16. Furuse Y, Suzuki A, Kamigaki T, Shimizu M, Fuji N, Oshitani H. Reversion of influenza A (H3N2) virus from amantadine resistant to amantadine sensitive by further reassortment in Japan during the 2006-to-2007 influenza season. J Clin Microbiol 2009;47:841-4.

17. Barr IG, Hurt AC, Iannello P, Tomasov C, Deed N, Komadina N. Increased adamantane resistance in influenza $\mathrm{A}(\mathrm{H} 3)$ viruses in
Australia and neighbouring countries in 2005. Antiviral Res 2007;73:112-7.

18. Simonsen L, Viboud C, Grenfell BT, et al. The genesis and spread of reassortment human influenza $\mathrm{A} / \mathrm{H} 3 \mathrm{~N} 2$ viruses conferring adamantane resistance. Mol Biol Evol 2007;24:1811-20.

19. Bean WJ, Threlkeld SC, Webster RG. Biologic potential of amantadine-resistant influenza A virus in an avian model. J Infect Dis 1989;159:1050-6.

20. Nelson MI, Simonsen L, Viboud C, Miller MA, Holmes EC. The origin and global emergence of adamantane resistant $\mathrm{A} / \mathrm{H} 3 \mathrm{~N} 2$ influenza viruses. Virology 2009;388:270-8.

21. Allen JE, Gardner SN, Vitalis EA, Slezak TR. Conserved amino acid markers from past influenza pandemic. BMC Microbiol 2009;9:77. 


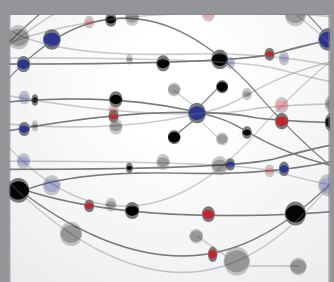

The Scientific World Journal
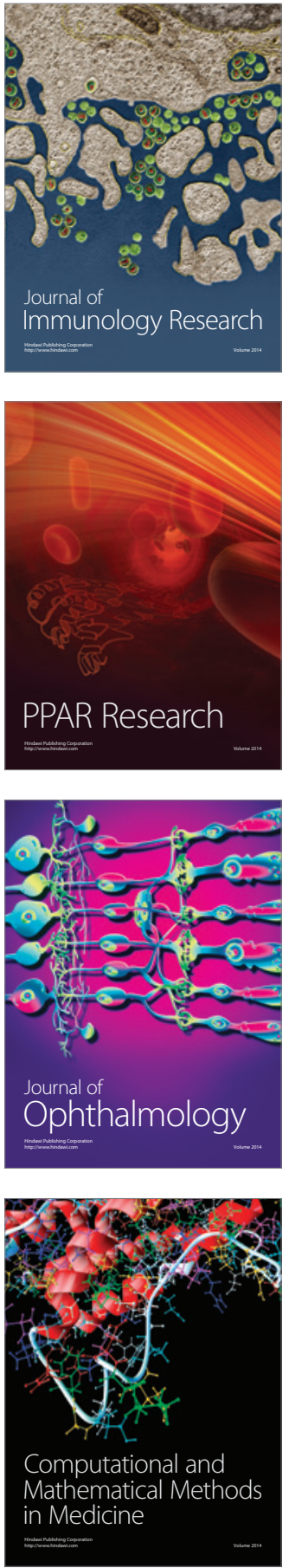

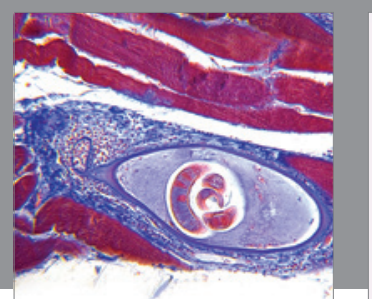

Gastroenterology Research and Practice

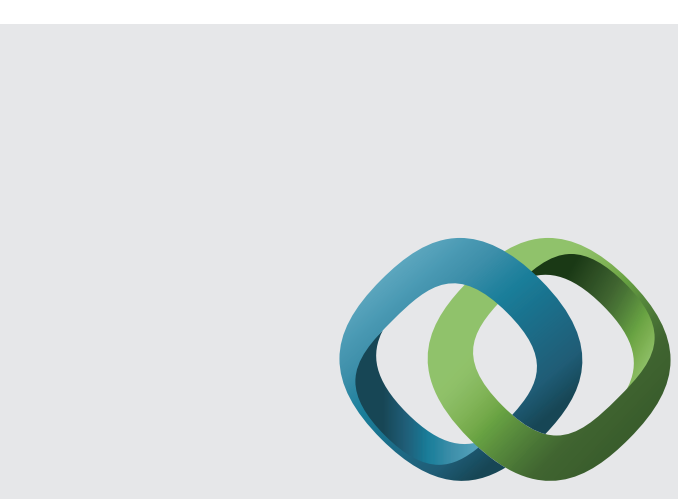

\section{Hindawi}

Submit your manuscripts at

http://www.hindawi.com
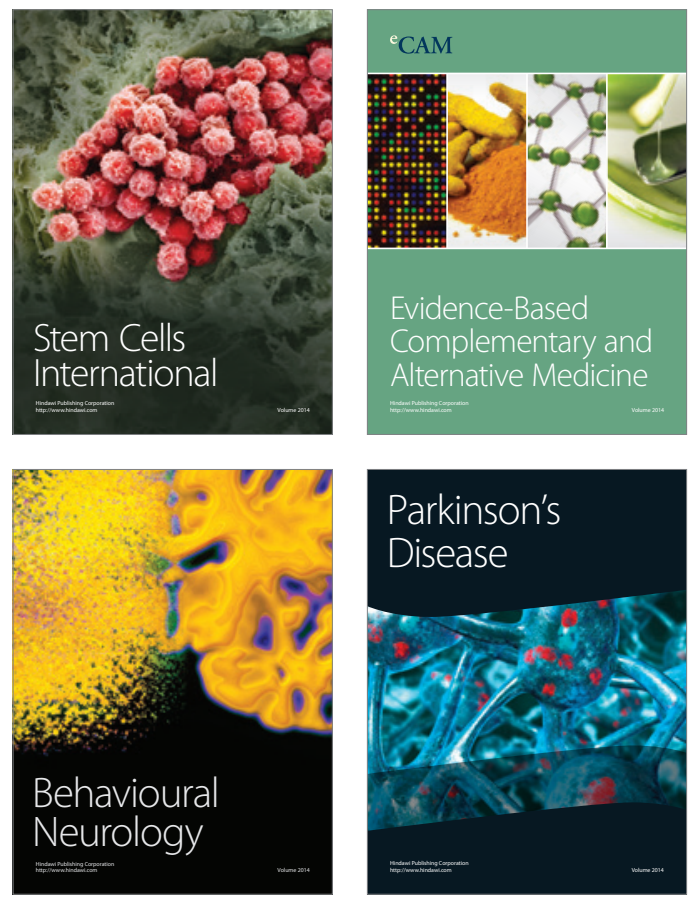
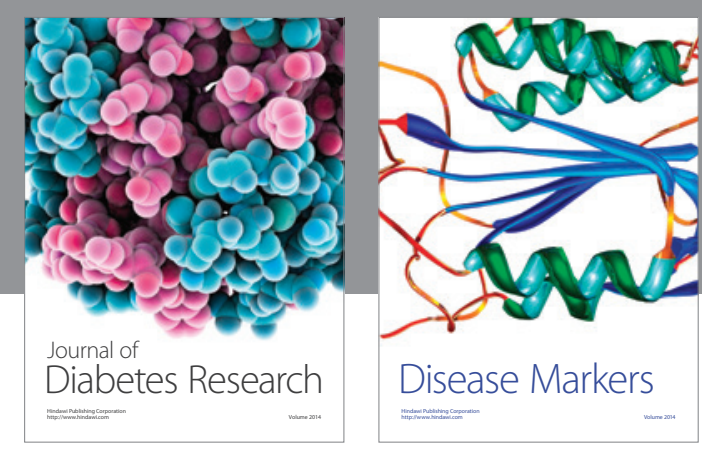

Disease Markers
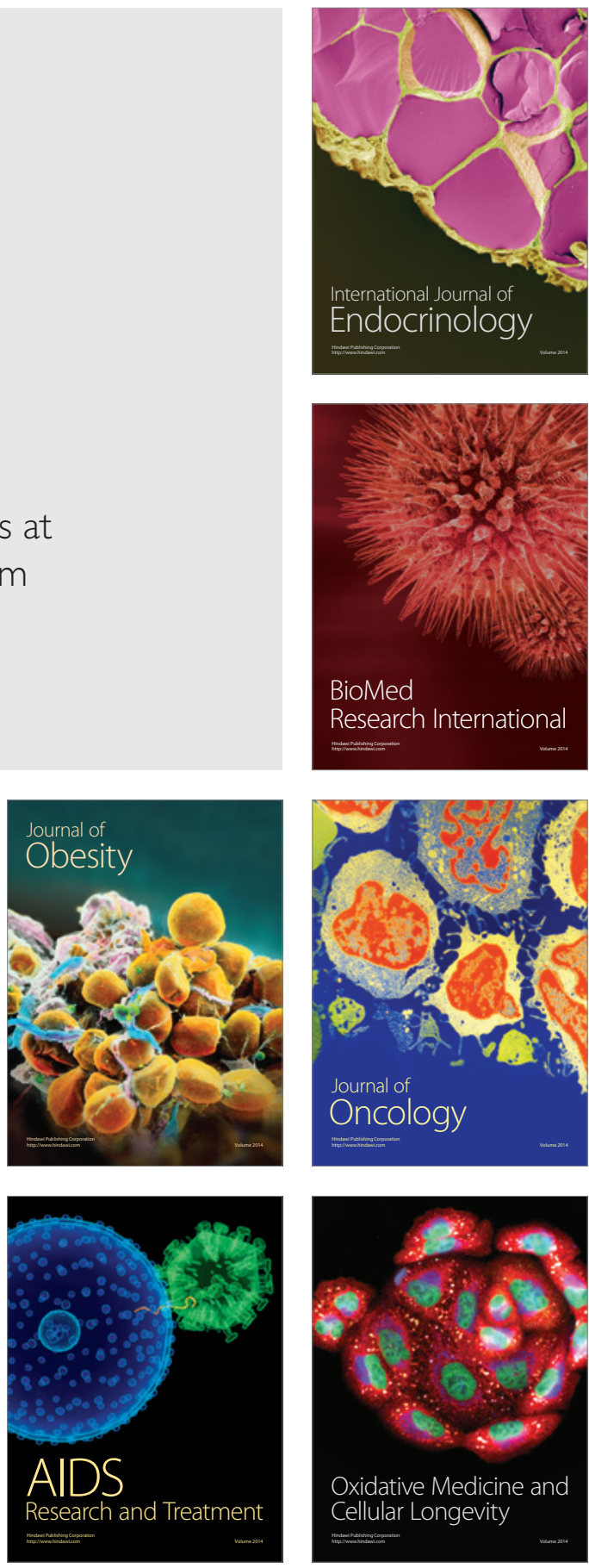